\title{
Towards a mobile flipped classroom: Using mobile instant messaging to enhance distributed learning of academically challenged students
}

\author{
Patient Rambe \\ Central University of Technology, South Africa
}

\begin{abstract}
While mobile devices have been touted by technology optimists as silver bullets for tackling the challenges of asymmetrical access to learning resources and 'fixing' inflexible traditional educator-dominated pedagogies, the irony is that educators' expectations for emerging technologies to mediate untransformed pedagogical practices have impeded the optimal utilisation of mobile applications like mobile instant messaging. Since profound shifts in pedagogical designs are necessary for the adoption of mobile instant messaging to ensure distributed collaborative learning by students, this study adopted a mobile flipped classroom to re-engineer pedagogical delivery. The mobile flipped classroom comprised the use of a mobile application (i.e. WhatsApp) by geographically dispersed students to collaboratively engage with content after demonstration of IT concepts and processes by the educator. Evidence from WhatsApp-enabled collaborative engagements (i.e. lecturer-student, student-peer) and in-depth interviews with students suggest that mobile flipped classrooms enabled student self-paced learning, heightened their access to distributed learning, enhanced their cogitative processes, promoted on-task activities and informal playback of academic videos watched by students. The study recommended that successful adoption of emerging technologies necessitates a consideration of student grasp of disciplinary knowledge, ability to work collaboratively and sustained willingness to engage on academically purposeful activities.
\end{abstract}

Keywords: Distributed collaborative learning; mobile instant messaging, WhatsApp, flexible learning

\section{Introduction}

Although the academic potential of mobile devices has been discussed over the past one and half decades, the capacity of mobile phones to enhance distributed mobile learning is a relatively new discourse in contemporary academic literature (Pocatilu et al., 2010; Winters, 2006). Distributed mobile learning describes the collaborative learning among geographically dispersed learning communities that is mediated by portable computing devices like mobile phones, smart phones and laptop computers.

While mobile applications are hailed for the opportunities they provide for students to work collaboratively in different environments (Uden, 2007), access shared resources simultaneously (i.e. concurrency) (Pocatilu et al., 2010) and accentuate learning flexibility by fitting learning into student work processes (Uden, 2007), these affordances cannot be assumed to guarantee distributed collaborative learning. This is because the realisation of distributed collaborative learning necessitates appropriate pedagogical strategies that draw on these mobile phone capabilities to enhance student learning seamlessly across temporal, spatial and time zones. Hamdan et al. (2013) warns that although educators are using emerging technologies (e.g. video, digital simulations and mobile instant messaging) to personalise learning for students, these technologies will have limited effects unless there are profound alterations to the traditional teaching model. Consistent with the need for transformed pedagogies, this study adopted a mobile flipped classroom to support the distributed collaborative learning of previously disadvantaged IT students at a South African university. Previously disadvantaged students (PDSs) are those that enter South African universities underprepared (academically, socially and even linguistically) to deal with academic complexities of tertiary education. 
In view of the foregoing discussion, the following research questions were posed: 1 . How can a mobile flipped classroom be designed to enhance the distributed collaborative learning of historically disadvantaged IT students? 2. What educational benefits did students accrue from using mobile flipped classroom?

\section{Literature review}

In a flipped model, lessons are delivered outside the class using available technologies and class time is harnessed for hands-on learning of students, collaboration with peers, evaluation of their progress and for provision of one-on-one assistance, guidance and inspiration by the educator (Hamdan et al., 2013). There are multiple educational benefits of flipped classrooms. For Caperton (2012), flipped learning can have a significant and scalable impact on students if technology is used to promote constructionist learning spaces and make students designers and owners of their learning. This makes mobile flipped classrooms ideal candidates for distributed collaborative learning as they combine student generation of content with individual and collaborative engagement with educational resources in distributed locations. For Horn (2013) this online instruction gives students ownership of learning by rewinding and re-viewing sections [of videos] they do not understand or fast-forwarding through material they have already mastered while in-class contact supports interactive engagement through practical problem solving, discussion and executing specific projects.

The flipped model, however, is not without its critics. It is often criticised for recycling traditional instruction through the back door under the guise of motivating students to learn and increasing contact time for engagement (group work, individual study, assessments etc.). For instance, Caperton (2012) critiques the flipped classroom for being indifferent to/ignoring the fundamentals of cognitive and social constructivism (which emphasise cognition and learning by doing) by emphasising speaker-centred instructional video tutorials, streaming of impersonal, frontal teaching or filmed lectures aimed at mass audiences. Nielsen (2011) warns educators to exercise caution when adopting flipped classrooms for several reasons: lack of home access to technologies by students, it does not compensate for poor pedagogical delivery, and the need for a careful redesign of the learning environment to meet learning needs of heterogeneous students.

\section{Theoretical Framework}

The theory of distributed learning provides human centric perspective on learning, which emphasises activity and usage of technology rather than technologies per se (Fischer \& Konomi, 2007). Fischer and Konomi's (2007) framework for the interpretation of distributed intelligence in mobile technologies stresses: Who is using device/application? What are they doing? Where are they doing it? 4 When are they able to do it? 5 Why are they doing it? 6 How do they do it? As such distributed learning mediated by mobile applications necessitates a rigorous analysis of human actors, their motivations, learning strategies and activities, embedded social and cultural practices, and their situated contexts of interaction.

For Winters (2006), a distributed learning perspective necessitates that the technology assumes a secondary role while the situated context, social considerations (such as communication and appropriation) and learning activities are given more 
preponderance. Emphasis is placed on: learning activities, access to information and people, communication, community building and appropriation. Oblinger and Maruyama (1996) argue that effective learning environments should advance knowledge about the ways students learn and the obstacles they face (cognition), student meaningful interactions with information, peers and educators (collaboration), access to powerful communication to reach colleagues, experts and diverse information (communication) and student familiarity with technology uses to transform student learning experiences (computing). The table below summarises the interpretive and analytical framework adopted in this work.

Table 1: Analysis of distributed learning through networked mobile devices

\begin{tabular}{|c|c|c|c|}
\hline Category & $\begin{array}{l}\text { Fischer and Konomi } \\
(2007)\end{array}$ & Winters (2006) & $\begin{array}{l}\text { Oblinger and Maruyama } \\
\text { (1996) }\end{array}$ \\
\hline Human actors & $\begin{array}{l}\text { Who is using the mobile } \\
\text { application? }\end{array}$ & People (learners, peers, teachers) & $\begin{array}{l}\text { Student, peers and } \\
\text { educators }\end{array}$ \\
\hline $\begin{array}{l}\text { Human } \\
\text { motivations }\end{array}$ & Why are they doing it? & & Cognition \\
\hline $\begin{array}{l}\text { Teaching/ learning } \\
\text { designs and } \\
\text { activities }\end{array}$ & What are they doing? & $\begin{array}{l}\text { Learning activities (motives, creativity, } \\
\text { knowledge building, co-construction), }\end{array}$ & $\begin{array}{l}\text { Collaboration } \\
\text { Content creation }\end{array}$ \\
\hline $\begin{array}{l}\text { Socio-cultural } \\
\text { practices }\end{array}$ & How do they do it? & $\begin{array}{l}\text { Communicating (conversations and } \\
\text { discourse); } \\
\text { Appropriating (interaction and levels of } \\
\text { engagement); } \\
\text { Learning informally (prior experiential } \\
\text { learning, socialisation, distributed learning } \\
\text { networks) } \\
\text { accessing information (sharing, moving) }\end{array}$ & $\begin{array}{l}\text { Appropriation (interaction } \\
\text { and levels of engagement) } \\
\text { Access to communication } \\
\text { On demand access to } \\
\text { networks and educational } \\
\text { resources from distributed } \\
\text { locations }\end{array}$ \\
\hline $\begin{array}{l}\text { Technological } \\
\text { affordances }\end{array}$ & $\begin{array}{l}\text { When are they able to do } \\
\text { it? }\end{array}$ & & $\begin{array}{l}\text { Computing, storage and } \\
\text { management of } \\
\text { information }\end{array}$ \\
\hline Situated contexts & Where are they doing it? & Community & \\
\hline
\end{tabular}

\section{Methodology}

A virtual ethnographic approach was adopted to unravel the pedagogical design of a mobile flipped classroom, students' experiences of its educational benefits they accrued from its use. Virtual ethnography involves the adoption of interpretive methodologies by a researcher participating in the field to capture and document the lived experiences of participants (Fouchè \& Schurink, 2011). The researcher was a participant observer in a second year IT course at South African university in which geographically distributed PDSs used a mobile instant messaging application (i.e. WhatsApp) to voluntarily consult with their educator afterhours (6-8pm) in preparation for the following lectures. The student-peer and educator student interactions on WhatsApp, which lasted 6 months, involved clarifications and discussions of complex IT concepts, which were given as an assignments on a weekly basis. While web metrics were not conducted to evaluate the rate of participation, the postings per group demonstrated sub-optimal participation in many groups. However, conversations were well structured around questions peers posed to their groups and those posed by the educator to all groups. Few cases of student discussion of extracurricular interests and sharing humour stories were evident because the educator stipulated that WhatsApp was to be used for academic discussion exclusively.

Adopting virtual ethnography, the ethnographer often captures the perspectives of the informants where the interaction happens with the intention of studying the cultural 
concepts and generating a cultural portrait (Fouchè \& Schurink, 2011, p. 315). Mindful of researcher's experience in IT related issues, the IT educator whose class the researcher studied first solicited the researcher's social presence on WhatsAppmediated student clusters for a duration of a semester and a half (approximately 6 months). The researcher' role was: 1 . To informally track discursive trajectory of the lecturer-student and student-peer conversations on WhatsApp. 2. To provide on demand IT support and guidance to student queries only in situations where the educator was unavailable. 3. To make meaning from the data (queries, questions and answers) that student generated through their consultations with peers and their educator. 4. Make suggestions to the IT lecturer about improving pedagogical design of the WhatsApp consultative environment.

\section{Design of the flipped classroom}

Most PDSs complained to educator about limited contact time and their difficulties in understanding complex IT concepts in lectures. The educators then considered WhatsApp as a "trendy" communication tool among students that could support distributed collaborative learning. Subsequently, he encouraged students to download WhatsApp mobile service onto their mobile phones. He then split the class of 93 students into 14 clusters, assigned all students to clusters comprising between 8-12 students in addition to the lecturer. To ensure the "anonymity" of interactants and to foreground academic interactions and consultations, students were expected to save their cluster members' mobile numbers on WhatsApp as their IDs. While it was possible for a member to know other members if s/he saved their numbers, the size of the class and/ groups meant that it was not automatically guaranteed to know everyone in the group. The lecturer, however, saved both the cluster members' names and mobile numbers so that he could authenticate the participants' identities as well as trace the trajectory of distributed collaborative learning.

The educator normally gave short 10 minutes lectures on a concept via screen cast followed by two IT questions to all clusters so that they could consult with peers via WhatsApp. As a guest participant, the researcher maintained social presence in all clusters to track student conversations while the educator scaffolded students in problem solving when they were stranded. Materials availed on WhatsApp (the screen casts of educator's lecture, additional resources, peers and the guest) served as educational resources for student preparation for classroom sessions the following day. The sessions focused more on clarification of concepts discussed in screen casts, critical questioning by students and group discussions of answers the peers and educators provided on WhatsApp. In class, students were tasked to form small groups (4-7 members) and to discuss their interpretations of the online discussions and write their reflections down. They would then exchange their reflections with other groups and critique other groups' reflections. Thereafter, a representative from each group would be tasked to summarise their critique on peer groups' reflections. This hands-on approach allowed all group members to participate as well as train students to improve their intra and inter-communication skills.

\section{Data Analysis}

The educator authorised the researcher to download all postings on his interactants with students on WhatsApp (data mining), printed and analysed them thematically to develop themes and categories as shown in Table 2 below. In thematic content analysis, researchers identify topics or themes by means of line-by-line analysis, continually 
name categories by comparing new data incidents with categories already identified (Schurink et al., 2011). Themes were drawn from the topics discussed and messages embodied in the postings to develop a nuanced analysis of the postings. The themes were then compared with the theoretical framework (Fischer \& Konomi, 2007; Oblinger \& Maruyama, 1996; Winters, 2006) to provide a unified analytical framework as shown in the Table 2. Categories that emerged related to human actors, pedagogical motivations, pedagogical activities, learning designs and social and cultural practices.

Table 2: Analysis of distributed learning through WhatsApp-enhanced flipped classrooms

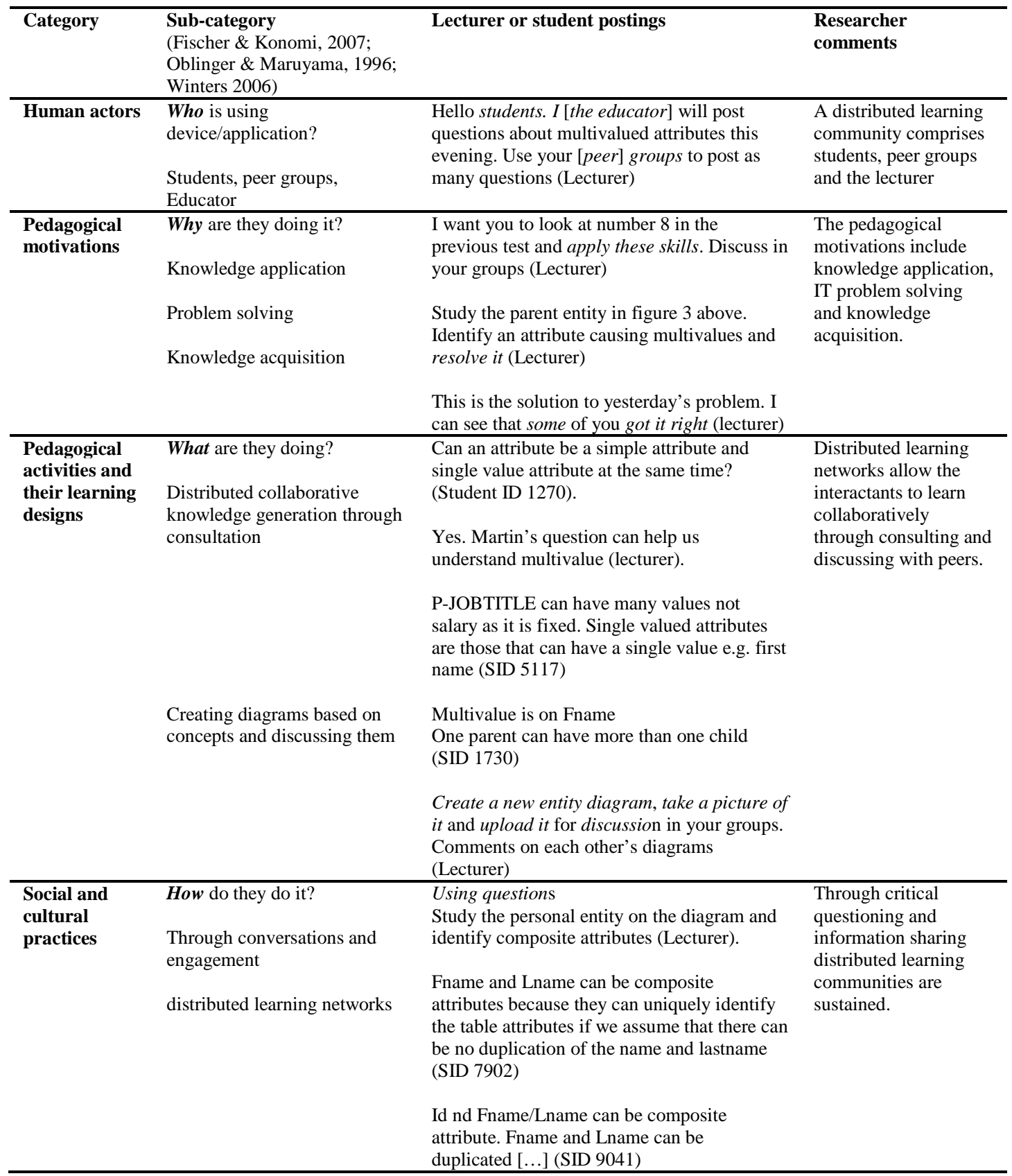

\section{Interviews}

The interviews were conducted in the second semester with 43 students to establish the appropriate pedagogical design that could support distributed learning of historically disadvantaged IT students and the educational benefits of a WhatsApp-mediated flipped classroom. A focus on historically disadvantaged students was to ensure their 
academic inclusion as they felt alienated by self-regulated learning normally expected of them at university. The interviews lasted about 40 minutes and were conducted in lab foyers where students often "hanged out". The transcripts were audio-recorded transcribed verbatim and analysed thematically

\section{Findings}

The research questions and the analytical framework guided the reporting results.

\section{Pedagogical design of mobile flipped classrooms}

The pedagogical design of mobile flipped classrooms necessitated the involvement of human actors (i.e. educator, students and peer groups) who collaboratively worked on learning tasks and activities through questions, contributions and meaningful engagement with learning resources. Under the human actors category the following distinct issues emerged: meaningful academic activities (focusing on cogitative processes), persistent social presence and anonymous interaction. These are discussed in detail is the following sections.

\section{Meaningful cogitation}

Human actors mediated the pedagogical design and effective application of mobile flipped classrooms, which comprised short recorded video lectures which students watched via screen cast followed by educator-student and student-peer engagements on WhatsApp. A learning strategy that necessitated their participation in authentic academic task activities (such as watching short video lectures, critical questioning and peer group discussions) was pivotal in sustaining meaningful cogitation and collaborative engagement among these geographically-remote online communities (see educator and student postings under human actors in Table 2 and Table 3 respectively). Yet effective student cogitation required activities that combined collaborative studentpeer interaction, authentic construction of knowledge and complex problem solving to increase student mastery of IT concepts. These complementary issues are addressed in subsequent sections.

\section{Persistent social presence}

Besides the foregrounding of academic tasks and group learning activities by human actors, the design of mobile flipped classrooms necessitated the continued social presence and strategic positioning of the educator as a "guide on the side", mentor and resource consultant. A scaffolding strategy involving intensified guidance to students during the inceptive phases of collaborative interaction followed by "fading" (i.e. gradually reducing the level of support with increased student mastery of concepts) was only feasible when students demonstrated progressive mastery of complex concepts and problem solving. As such, the complaints about educators' delayed responses that contributed to student anxiety and frustration can be interpreted as student misconceptions about scaffolding by the educator. The following student complaints about delayed responses and the educator's response are symptomatic of academically challenged students' expectations for educators to be "on their backs":

I said da same thng so many times bt u didn't say anything (Student post).

I saw that your answer was correct but I wanted to give other a chance to respond but thanks for picking discrepancy (Educator post).

Lol, I think we shd then wait for sir to set us straight (Peer's post). 
Although WhatsApp-mediated flipped classrooms were designed to provide an ambient environment for optimising academic engagement through anonymous consultations, the pressure to participate often exposed academically-challenged students' lack of understanding of IT problems. Some learning contradictions manifested in student comfort in fictitious participation on the one hand and their feeling of impotence when they sensed that their postings were bordered on ignorance on the other (see the posting below).

We are all going to get lost without some direction. Hehehe, I might just convince myself that all I say is correct and we all know that I know ZERO (Student post)

\section{Anonymous interactions}

The pedagogical design of mobile flipped classrooms necessitated anonymous interactions to foreground impersonal and authentic academic interactions as well as guard against asymmetrical academic engagement caused by differential student learning capabilities and digital literacies. The educators designed WhatsApp-based clusters to support anonymous interactions by requiring students to use their phone numbers as personal IDs. Anonymous interactions protected the identity of shy, less confident, and academically challenged students who struggled to express their views publicly online. One low self-esteem student explained in an interview: "I like WhatsApp [anonymous] interactions because I can pose questions without feeling inferior to my peers. This is unlike face-to-face contact session where I feel exposed if I pose a question or make a statement publicly (STD 14). Another previously disadvantaged student concurred: "I am shy to ask questions face-to-face so I prefer to ask on WhatsApp, and if I missed class I can always access things done in class.”

\section{The educational benefits of WhatsApp-based flipped classrooms}

\section{Pedagogical motivations and activities}

Pedagogical motivations and activities of WhatsApp flipped classrooms shaped and influenced educational outcomes of these classrooms. The design's motivations included increasing student reflection, promoting practical application of knowledge, enhancing problem solving, supporting on-demand learning by students and private study. The pedagogical activities included drawing IT diagrams, capturing them using mobile phone camera and posting them online, understanding and identifying the different concepts the diagrams illustrated, critical questioning and complex problem solving, group contributions and explaining complex concepts.

Given the fragmentation of student-led discussions and the educator's scaffolding strategy that involved non-interference in student discussions to allow them to explore and generate solutions, the aforementioned educational benefits were not always realised consistently. The following section discusses the major educational benefits of the WhatsApp-based flipped classroom identified in the study.

\section{Student reflection}

WhatsApp flipped classrooms promoted critical reflection through asynchronous discussions that enabled student cogitation before formulating questions, answers and critique. Asynchronous conversations shielded students from the urgency of immediate responses normally characteristic of traditional classrooms: 
Flipped classes (using WhatsApp) are self-empowering because they allow me to think critically before answering questions (STD 43). (WhatsApp) gives me more time to think about the videos I watch, formulate and change my answers (STD 09)

Replaying videos provided opportunities "to repeat sections / points I did not understand unlike in class where I am scared to ask or interrupt" (STD 28) suggest the ambience of WhatsApp flipped classrooms for academically struggling students.

\section{Self-paced learning}

Short video lectures and WhatsApp discussions allowed academically at-risk students who normally struggled with the swift pace of lectures to self-pace their learning without the additional pressure of having to capture everything the lecturer taught:

With flipped classrooms I get watch videos and do my work at my own time, therefore it is relatively easier to handle the pressure (STD 30)

It requirements for individual effort and interaction allow me to do tasks at an easier pace with more information at hand (STD 16)

All these views point to the flexible and self-management opportunities embedded in productive use of flipped classrooms.

Problem solving

Since IT is a significantly problem-based discipline, the use of WhatsApp allowed students to propose solutions to social technical and human related problems. Both the lecturer and students drew on paper some technical IT diagrams, which represented problems relating to various concepts (e.g. simple attributes, single valued attributes and multivalued attributes), photographed them using their mobile devices and uploaded them on WhatsApp for discussion. The affordances for uploading images of diagrams, open dialogue and collaborative knowledge constructions were the distinct educational benefits of lecturer-student and student-peer discussions via WhatsAppenhanced flipped classroms.

\section{Discussion}

\section{Student-centred and context-aware designs}

A realistic pedagogical design of a mobile flipped classroom, which enhanced the distributed learning of academically challenged IT students necessitated a broader understanding and incorporation of student needs, authentic learning activities and socio-cultural context into the design of this learning environment. Practically, the design involved making appropriate choices about the lecture content to be delivered and the available video technologies that would support the delivery of this content. In this study, students watched the video lectures mainly using WhatsApp in addition to YouTube or Vimeo, depending on their availability. More so, a developmentally appropriate flipped design necessitates recognition of the fact that no student in a particular cohort is at the same level of psychological development at any given time (Nielsen, 2011). Findings revealed that some PDSs lacked confidence and self-esteem in WhatsApp group collaboration due to communication difficulties and fear of public expression of their views. Notwithstanding the lurking of some students, anonymous 
communication overall, served to equalise participation among these academically challenged students.

Hamdan et al. (2013) highlight that the design of the flipped learning model necessitates a deliberate shift from a teacher-centred classroom to a student-centred approach that allows students to choose when and where they learn. In these flexible learning environments, in-class time is meant for exploring topics in greater depth and creating richer learning opportunities (Ibid). While bridging student learning context and learning needs is an inexorably complex matter, our finding suggests that studentcenteredness and context-sensitive designs are achievable through de-emphasising the technology and foregrounding human actors, pedagogical motivations and pedagogical activities in context. Emphasising the interface between human actors (educator, students and peer groups), their pedagogical tasks and activities in context (cogitative processes, anonymous collaborative interactions, sustained educator-directed support systems) advanced the learning trajectory of students through: increased focus on authentic learning tasks, enhanced student psychological development and empowerment of subdued voices to contribute publicly to discussions. From a distributed learning perspective, designing a student-centred learning context necessitates an adaptation of individual students' social and physical environment to suit their information needs, enabling new forms of learning support through ubiquitous multimodal notifications, ubiquitous multimodal messaging and ubiquitous content exchange and sharing (de Jong et al., 2008, p. 120).

\section{Persistent social presence}

To promote meaningful interactions and balanced participation from all group clusters, the design of the mobile flipped classrooms required the continued social presence of the educator. Social presence ensured persistent provisioning of support from educators, tracking effective utilisation of education materials by students, reducing parasitic behaviour engrained in lurking, and guarding against discussions of little substance and the "tyranny of participation". As such, for mobile flipped classrooms to support distributed learning, they need to: provide tools for learning grounded in a 'scaffolding with fading' perspective and autonomous performance by students (Fischer \& Konomi, 2007) to enhance the participation of academically challenged students. Such design should also provide support not only to individuals but to groups and communities, exploit the power of social creativity based on informed participation (Fischer et al., 2005) and contextualize generic systems to person and task-specific environments (Fischer, 2001). In our study this necessitated understanding of students' psychology (confidence in public online participation, internet access, and selfregulation behaviour) to ensure meaningful, balanced participation.

\section{Social-constructivist learning}

The educational benefits of mobile flipped classrooms laid in their potential to support knowledge-centred learning, engender social constructivist learning and authentic interactional environments. Students reported that the adoption of the mobile flipped classrooms to support educator-student and student-peer engagements allowed them to reflect on content and foreground more critical questioning. This finding buttresses Marlowe's (2012) findings that flipped classrooms improved student desire to explore concepts they found interesting in greater depth as well as their semester grades. Although the current study identified no marked improvement in the student grades, evidence of lurking by some students on WhatsApp co-existed with manifestations of increased participation in academic tasks and activities on WhatsApp compared to face- 
to-face lectures. This buttresses claims that the learning gains from flipped classroom remain unsubstantiated: as there is lack of evidence on measurement of the practice or assessment of its impact on student learning (Horn, 2013).

\section{Conclusion}

The study investigated how the mobile flipped classroom could be designed to support distributed collaborative learning of academically challenged students, explored the educational benefits that could be derived and learning barriers to be overcome by this intervention. Evidence suggests that human actions (i.e. anonymous interactions, meaningful cogitation and persistent social presence of educators), meaningful pedagogical motivations and activities (reflection, self-paced learning, problem solving) were critical to the design of mobile flipped classrooms. The latter also constituted educational benefits of using flipped classrooms while erratic connectivity, communication delays and limited self-discipline impeded coherent distributed collaborative learning.

\section{References}

Caperton, I.H. (2012). Education trends: Before we flip classrooms, let's rethink what we're flipping to. Edutopia blog (Posted October 17, 2012)

http://www.edutopia.org/blog/rethinking-the-flipped-classroom-idit-harel-caperton

de Jong, T., Specht, M., \& Koper, R. (2008). A reference model for mobile social software for learning. International Journal of Continuing Engineering Education and Lifelong Learning, 18(1), 118-138.

Fischer, G. \& Konomi, S. (2007). Innovative socio-technical environments in support of distributed intelligence and lifelong learning. Journal of Computer Assisted Learning, 23, 338-350.

Fischer G., Giaccardi E., Eden H., Sugimoto M. \& Ye, Y. (2005). Beyond binary choices: integrating individual social creativity. International Journal of Human-Computer Studies, 63, 482-512.

Fischer G. (2001). User modeling in human-computer interaction. User Modeling and User-Adapted Interaction (UMUAI), 11, 65-86.

Fouchè, C. \& Schurink, W. (2011). Qualitative research designs. In A. De Vos, H. Strydom, C. Fouche, \& C. Delport (Eds), Research at grassroots: For the social sciences and human service professions (pp. 307-327), Pretoria: Van Schaik Publishers.

Hamdan, N., McKnight, P., McKnight, K. \& Arfstrom, K. (2013). The flipped learning model: A White Paper based on the Literature review titled a review of flipped learning. The flipped learning Network.

Horn, M. (2013). The transformational potential of flipped classrooms: Different strokes for different folks. Education next, 13(3), Accessed online

http://educationnext.org/the-transformational-potential-of-flipped-classrooms/

Marlowe, C. (2012). The effect of the flipped classroom on student achievement and stress Masters Thesis, Montana State University, Bozeman, Montana.

Nielsen, L. (2011). Five reasons i'm not flipping over the flipped classroom. Teaching and Learning Advisor Blog (Posted Nov 8, 2011)

http://www.techlearning.com/Default.aspx?tabid=67\&EntryId=3379

Oblinger, D. \& Maruyama, M. (1996). Distributed Learning. CAUSE Professional Paper Series, Boulder, Colorado.

Pocatilu, P., Doinea, M., \& Ciurea, C. (2010). Development of distributed mobile learning systems. CSECS '10 Proceedings of the 9th WSEAS international conference on Circuits, systems, electronics, control \& signal processing (pp. 196-201), Wisconsin, USA.

Schurink, W., Fouchè, C. \& De Vos, A. (2011). Qualitative data analysis and interpretation. In A. De Vos, H. Styrdom, C. Fouchè \& C. Delport (Eds), Research at grassroots: For the social sciences and human service professions (pp. 397-423). Pretoria: Van Schaik.

Uden, L. (2007). Activity theory for designing mobile learning. International Journal of Mobile Learning and Organisation, 1(1), 81-102.

Winters, N (2006). What is mobile learning? In M. Sharples, (Ed). Big issues in mobile learning. Report of a workshop by the Kaleidoscope Network of Excellence Mobile Learning Initiative, University of Nottingham. 